\title{
How Water Content Can Influence the Chemomechanical Properties and Physical Degradation under Aging of Experimental Adhesives
}

\section{Stella Renata Machado Silva Esteves, ${ }^{1}$ Daphne Camara Barcellos, ${ }^{2}$ Tânia Mara da Silva, ${ }^{3}$ Mateus Rodrigues Silva, ${ }^{4}$ Tiago Moreira Bastos Campos, ${ }^{1}$ Elizabeth Pimentel Rosetti, César Rogério Pucci $\mathbb{D}^{1},{ }^{1}$ and Sérgio Eduardo de Paiva Gonçalves ${ }^{1}$}

\author{
${ }^{1}$ Department of Restorative Dentistry, Institute of Science and Technology of São José dos Campos, \\ Sao Paulo State University (Unesp), São Paulo, Brazil \\ ${ }^{2}$ Department of Prosthodontics, Federal University of Espírito Santo, Vitória, ES, Brazil \\ ${ }^{3}$ Anhanguera College \& University of São José Dos Campos, São Paulo, Brazil \\ ${ }^{4}$ Technical Institute of Aeronautics, São Jose dos Campos, São Paulo, Brazil
}

Correspondence should be addressed to César Rogério Pucci; cesar@fosjc.unesp.br

Received 30 November 2021; Revised 18 January 2022; Accepted 2 February 2022; Published 27 February 2022

Academic Editor: Carlos A. Munoz-Viveros

Copyright $\odot 2022$ Stella Renata Machado Silva Esteves et al. This is an open access article distributed under the Creative Commons Attribution License, which permits unrestricted use, distribution, and reproduction in any medium, provided the original work is properly cited.

\begin{abstract}
Objective. To evaluate the physicochemical (sorption (SOR), solubility (SOL), and degree of conversion (DC)) and mechanical (flexural strength (FS), modulus of elasticity (ME), and compressive strength (CS)) properties of adhesives with different water contents $\left(\mathrm{D}_{2} \mathrm{O}\right)$. Materials and Methods. An adhesive was formulated: 55 wt\% BisGMA, 45 wt\% HEMA, 0.5 wt\% camphorquinone, $0.5 \mathrm{wt} \%$ EDMAB, and $1.0 \mathrm{wt} \%$ DPIHP. $\mathrm{D}_{2} \mathrm{O}$ was added into the adhesives $(0 \mathrm{wt} \%, 10 \mathrm{wt} \%$, and $16 \mathrm{wt} \%)$. DC was monitored through the FTIR. FS, ME, CS, SOR, and SOL were tested. The adhesive samples were aged in deionized water, ethanol, and acetone. Data were submitted to ANOVA and Tukey's tests (5\%). Results. For DC, the $0 \mathrm{wt} \%$ group showed a significant reduction $\left(68.09 \pm 0.14_{\mathrm{A}}\right)$ compared with the $10 \mathrm{wt} \%\left(87.07 \pm 0.81_{\mathrm{B}}\right)$ and $16 \mathrm{wt} \%$ groups $\left(89.87 \pm 0.24_{\mathrm{B}}\right) ; 10 \mathrm{wt} \%$ showed the highest FS $(\mathrm{MPa})$ mean values $\left(141.6 \pm 6.71_{\mathrm{B}}\right)$ compared with the $0 \mathrm{wt} \%\left(109.4 \pm 20.5_{\mathrm{A}}\right)$ and $16 \mathrm{wt} \%\left(107.8 \pm 15.8_{\mathrm{A}}\right)$. For the CS $(\mathrm{MPa})$ and $\mathrm{ME}(\mathrm{GPa})$, the $16 \mathrm{wt} \%$ showed the lowest mean values $\left(98.8 \pm 18.0_{\mathrm{B}}\right.$ and $2.2 \pm 0.3_{\mathrm{B}}$, respectively) compared with the $10 \mathrm{wt} \%$ and 0 wt $\%$. For the SOR, $16 \mathrm{wt} \%$ of water showed the highest mean values and the ethanol showed the lowest mean values of SOL regardless of water content. Conclusion. The amount of water content and the types of aging solvents significantly affect the adhesive properties.
\end{abstract}

\section{Introduction}

Dental composites are becoming more popular because of their strength, rapidness, and control of polymerization and aesthetic appearance. However, there is a large percentage of failures in a short period in these restorations [1]. Failures of composite restorations are observed mainly at the dentin/ adhesive interface. The factor for the long-term success of the composite restoration is the integrity of the adhesive bond layer with the presence and quality of the hybrid layer [2].
The factors that limit the durability of the adhesive layer are incomplete polymerization, partial infiltration of the adhesive into the demineralized dentin matrix, phase separation, and hydrolytic degradation of the adhesive interface [3].

The moisture of the dentin substrate after acid etching preserves the interfibrillar spaces of the collagen network for infiltration of the adhesive and builds a homogeneous hybrid layer [4]. However, clinically, there is a difficulty in controlling the humidity. Excess water forms water blisters 
inside the adhesive, and phase separation at the adhesive/ dentin interface has appeared as a new type of bond defect [5], dilutes the hydrophilic adhesive monomer and plasticizer polymer, and accelerates degradation of the adhesive interface [6].

Ye and colleagues [7] developed a ternary phase diagram of a dentin adhesive model composed of BisGMA (bisphenol A-glycidyl methacrylate), HEMA (hydroxyethyl methacrylate), and water. This ternary phase diagram provides valuable quantities of information regarding miscibility, distribution ratio, and phase portioning of the three components [7]. The hydrophilic-rich phase is composed primarily of water and HEMA. Under clinical conditions, the amount of water in the composition of the adhesive system should probably affect the adhesive stability, can limit the polymerization of the hydrophilic-rich phase, and leach HEMA to the surrounding tissues, inducing apoptosis [8], interfering in DNA synthesis. With the production of reactive oxygen species [9] and the expression of type I collagen by gingival fibroblasts, inhibition of mineral formation of dentin can occur [10]. In addition to the water from the hydrated dentin through the osmotic process, which may be increased by the presence of pulpal pressure, the dental adhesive can also present water sorption from the wet oral environment [11].

In the oral environment, the composite restorations are continuously exposed to chemical agents found in saliva, food, and drinks. These agents, when associated with temperature changes and dynamic load during chewing, may affect the long-term properties of a composite in the mouth [12]. Some organic solvents have the potential to damage the polymer structure of a composite [13]. It has been reported that the immersion in solvents also accelerates the degradation of the material, softens the polymer matrix through plasticization, and facilitates the release of unreacted monomers and degradation products, inducing similar effects already mentioned with regard to the wet environment [14].

Therefore, the objective of the present study was to evaluate the chemomechanical properties and physical changes under aging with different types of solvents of experimental adhesive with different water contents $\left(\mathrm{D}_{2} \mathrm{O}\right)$. Thus, the null hypotheses tested were as follows: (1) the model adhesive with different water contents $\left(\mathrm{D}_{2} \mathrm{O}\right)$ could not achieve similar results for the chemomechanical and physical properties; (2) the different aging solvents could not induce similar effects in the physical (sorption/solubility) properties of the experimental adhesives.

\section{Materials and Methods}

2.1. Model Adhesive Compositions. The model adhesive consisted of HEMA (Sigma-Aldrich, St. Louis, MO, USA) and BisGMA (Sigma-Aldrich, St. Louis, MO, USA) with a mass ratio of 45/55 (HEMA/BisGMA). The photoinitiators used were as follows: $0.5 \mathrm{wt} \%$ camphorquinone (CQ) as a hydrophobic photosensitizer, $0.5 \mathrm{wt} \%$ ethyl-4-(dimethylamino)benzoate (EDMAB) as a hydrophobic reducing agent, and 1.0 wt $\%$ diphenyliodonium hexafluorophosphate (DPIHP) as a hydrophilic coinitiator (all from SigmaAldrich, St. Louis, MO, USA). The neat resins were prepared in brown glass vials and stirred for $48 \mathrm{~h}$ to form a homogeneous solution [15].

$\mathrm{D}_{2} \mathrm{O}$ (99.9\%; Sigma-Aldrich, St. Louis, MO, USA) was added into the neat resins in variable amounts: $0 \mathrm{wt} \%, 10 \mathrm{wt}$ $\%$, and 16 wt $\%$, based on [5]. These concentrations of $\mathrm{D}_{2} \mathrm{O}$ were added according to a ternary phase diagram [16]. $\mathrm{D}_{2} \mathrm{O}$ (heavy water) was used instead of water to avoid coincidence of the peaks at the spectrum in the FTIR [16].

2.2. Degree of Conversion (DC). The DC was monitored in situ with an infrared spectrometer (FTIR/ATR, PerkinElmer, Waltham, MA, USA) with a resolution of $4 \mathrm{~cm}^{-1}$.

A volume of $10 \mu \mathrm{L}$ of the experimental adhesive model was placed on the ATR crystal, and a transparent coverslip was attached with a piece of tape placed on the sample to prevent the evaporation of components [6]. A 20-s-exposure to the LED unit (Demi Light Curing System, Kerr Corporation, USA), at an intensity of $1200 \mathrm{~mW} / \mathrm{cm}^{2}$, was initiated after the 50 spectra had been recorded. Real-time infrared spectra were continuously recorded for $600 \mathrm{~s}$ : before, during, and after light curing [17]. A time-resolved spectrum collector (Spectrum TimeBase, PerkinElmer, MA, USA) was used for continuous and automatic collection of spectra during light curing.

The DC was determined using the following equation, which was based on the intensity band ratios (peak area) before and after light curing (from $1638 \mathrm{~cm}^{-1}$ to $1608 \mathrm{~cm}^{-1}$ ) [16] (equation (1)). The DC was carried out in triplicate, and the results were averaged. The rate of polymerization was determined by taking the first derivate of the time vs. DC curve.

2.3. Flexural Strength and Modulus of Elasticity. Ten specimens of each group ( $0 \mathrm{wt} \%, 10 \mathrm{wt} \%$, and $16 \mathrm{wt} \% \mathrm{D}_{2} \mathrm{O}$ ) were prepared. The uncured adhesive model was placed on rectangular silicon molds $(12 \mathrm{~mm}$ length $\times 2 \mathrm{~mm}$ width $\times$ $2 \mathrm{~mm}$ height) [18], which were covered with a Mylar strip and light cured from the top surface for $20 \mathrm{~s}$ (Demi LED Light Curing System) at 3 different positions (right, middle, and left). The bottom surface was also light cured for another $20 \mathrm{~s}$ each (right, middle, and left). Specimens were stored in distilled water for $48 \mathrm{~h}$ at $37^{\circ} \mathrm{C}$ to complete the polymerization.

The flexural properties were evaluated using a threepoint flexural strength test performed with a universal testing machine (EMIC DL-200 MF, São José dos Pinhais, $\mathrm{SP}$, Brazil), at a crosshead speed of $0.5 \mathrm{~mm} / \mathrm{min}$. Flexural strength was obtained by measuring the load at fracture, and the modulus of elasticity was calculated based on the recorded load deflection curves [19].

2.4. Compressive Strength. Ten specimens of each group were prepared using a silicon mold $(4.0 \mathrm{~mm}$ diameter $\times$ $8.0 \mathrm{~mm}$ height). 
The silicon mold was filled in four approximately $2.0 \mathrm{~mm}$ thick increments and light cured for $20 \mathrm{~s}\left(1200 \mathrm{~mW} / \mathrm{cm}^{2}\right.$; peak wavelength of $453 \mathrm{~nm}$; LED Light Curing System, Demi Plus, Kerr Corporation, WI, USA) for each layer. The last increment was covered with a Mylar strip and a glass slide and light cured for $20 \mathrm{~s}$. Additional light curing was performed for $20 \mathrm{~s}$ on each lateral face of the cylinder after the silicone mold was removed. Specimens were stored in individual vials for $48 \mathrm{~h}$ to complete the polymerization [20].

The specimens were evaluated under a compressive load in a universal testing machine with a crosshead speed of $1 \mathrm{~mm} / \mathrm{min}$, and the data were obtained.

2.5. Sorption and Solubility. Thirty disc-shaped specimens of each group ( $0 \mathrm{wt} \%, 10 \mathrm{wt} \%$, and $\left.16 \mathrm{wt} \% \mathrm{D}_{2} \mathrm{O}\right)$ were fabricated using a silicone mold $(6.0 \mathrm{~mm}$ diameter $x 2.0 \mathrm{~mm}$ height) [21]. Uncured adhesive was placed in the silicon mold. A Mylar strip and a glass slide were placed onto the silicon mold, and the adhesive was light cured for $20 \mathrm{~s}$. Additional light curing for $20 \mathrm{~s}$ was performed on the bottom of the specimen. Specimens were stored in a desiccator containing freshly dried silica gel [18]. After $24 \mathrm{~h}$, the specimens were weighed using an analytical balance of $0.0001 \mathrm{~g}$ (Mettler Toledo, OH, USA). This cycle was repeated until a constant mass (mi) was obtained.

The specimens of each group were randomly divided into three groups $(n=10)$, according to the aging solution: water, ethanol, and acetone. Next, the specimens were immersed in $1 \mathrm{ml}$ of aging solution at $37^{\circ} \mathrm{C}$ for 28 days. After this period, the specimens were removed, blotted dried, and reweighed (ms). The specimens were again dried inside a desiccator and weighed daily until a constant mass was achieved (md). The data were given in percentage of total loss of weight (solubility) or gain of weight (sorption) [20].

Sorption and solubility were calculated using equations (2) and (3).

2.6. Statistical Analysis. The obtained data of DC (\%), flexural strength $(\mathrm{MPa})$, modulus of elasticity $(\mathrm{GPa})$, and compressive strength $(\mathrm{MPa})$ were analyzed using one-way ANOVA and Tukey's test (5\%). For sorption (\%) and solubility (\%), data were tabulated and mean values were analyzed using two-way ANOVA and Tukey's test (5\%).

\section{Results}

Table 1 shows the adhesive DC, flexural strength, modulus of elasticity, and compressive strength. The results for the mechanical tests showed statistical differences among the concentrations. The adhesive model with $0 \mathrm{wt} \% \mathrm{D}_{2} \mathrm{O}$ showed the lowest mean values of DC compared with the $10 \mathrm{wt} \%$ and 16 wt $\% \mathrm{D}_{2} \mathrm{O}(p=0.0001)$. The experimental adhesive with $10 \mathrm{wt} \% \mathrm{D}_{2} \mathrm{O}$ showed the highest mean values of flexural strength compared to the other groups $(p=0.0007)$. For modulus of elasticity, the adhesives with $0 \mathrm{wt} \%$ and $10 \mathrm{wt} \%$ $\mathrm{D}_{2} \mathrm{O}$ showed higher mean values than the 16 wt $\% \mathrm{D}_{2} \mathrm{O}$ $(p=0.0108)$. Also, for compressive strength, the experimental adhesive with $16 \mathrm{wt} \% \mathrm{D}_{2} \mathrm{O}$ showed the lowest mean values $(p=0.0001)$.

Figure 1 presents the kinetic results corresponding to the light curing of the adhesives models with different amounts of deuterium in its formulation. Figure 1(a) presents the DC over time, and it is possible to observe an increase in conversion curve after 50 data collection, showing the light curing process from 30 to $50 \mathrm{~s}$. After this initial growth, the curves show little variation over time (adhesive stability after conversion). Figure 1(b) presents the polymerization rate over time. It is possible to observe that the effects were water dependent. These effects provided a decrease in the maximum polymerization rate, widened the peak of the derivative, and moved the maximum peak to longer times due to the increase in the amount of $\mathrm{D}_{2} \mathrm{O}$. Figure 1(c) presents the conversion rate by the $\mathrm{DC}$, which means how much the reaction speed varies according to the reaction regardless of time. The adhesive with 0 wt $\% \mathrm{D}_{2} \mathrm{O}$ had the highest conversion rates; however, this only occurred at the beginning of the reaction after the conversion of $40 \%(\alpha=0.4)$ of monomer, and there is a sharp drop in this reaction rate. The adhesives with 10 or 16 wt $\% \mathrm{D}_{2} \mathrm{O}$ had lower conversion rates, but their decrease was slower than the 0 wt $\% \mathrm{D}_{2} \mathrm{O}$.

To perform a kinetic study, the autocatalytic model represented by equation (4) was used. This equation lists four constants: $k$ (speed constant), $m$ (exponent of the autocatalytic term), $n$ (exponent of the reaction order term), and $c$ (reaction yield). The autocatalytic term corresponds to the free radicals present in the polymeric chains which increase the reaction speed. The reaction order term corresponds to the double bonds reacted, and with the increase in conversion, they would decrease the reaction speed in an antagonistic way to the autocatalytic term [19].

Figure 2 presents the polymerization rate by time as a function of conversion. In the experimental data presented in Figure 2, the kinetic model for the autocatalytic reaction was adjusted, and the results obtained from this model are presented in Table 2.

The autocatalytic models had a coherent fit to the experimental values, observing an increase in velocity as a function of the yield in the first half of the reaction and a decrease in velocity from different yield values. At the beginning, the products of the reactions themselves (propagation of polymerization) stimulate the conversion, and in the second stage, the phenomenon of chain termination occurs with a decrease in the polymerization rate.

Table 2 presents the kinetic constants of the equation for autocatalytic processes (equation (4)). The results showed that the addition of $\mathrm{D}_{2} \mathrm{O}$ to the adhesive models caused a progressive change in the kinetic constants. As the amount of $\mathrm{D}_{2} \mathrm{O}$ increased, there was a reduction in the speed constant $(k)$. The exponent of the autocatalytic term $(m)$ did not change significantly with an increase of $\mathrm{D}_{2} \mathrm{O}$ in the adhesive model. The exponent of the reaction order term $(n)$ was significantly reduced when comparing the $0 \mathrm{wt} \% \mathrm{D}_{2} \mathrm{O}$ with the $10 \%$ and 16 wt $\% \mathrm{D}_{2} \mathrm{O}$, but there was no difference between the $10 \%$ and $16 \mathrm{wt} \% \mathrm{D}_{2} \mathrm{O}$. The constant $c$, which corresponds to the extent of reaction, exhibited an increase in the extent of reaction due to the increase in the amount of $\mathrm{D}_{2} \mathrm{O}$ in the adhesive. 
TABLE 1: Mean \pm standard deviation and results of Tukey's test of degree of conversion, flexural strength, modulus of elasticity, and compressive strength of adhesives.

\begin{tabular}{lcccc}
\hline & Degree of conversion (\%) & Flexural strength (MPa) & Modulus of elasticity (GPa) & Compressive strength (MPa) \\
\hline $0 \mathrm{wt} \%$ & $68.09 \pm 0.14 \mathrm{~A}$ & $109.4 \pm 20.5 \mathrm{~A}$ & $2.7 \pm 0.2 \mathrm{~A}$ & $141.4 \pm 19.5 \mathrm{~A}$ \\
$10 \mathrm{wt} \%$ & $87.07 \pm 0.81 \mathrm{~B}$ & $141.6 \pm 6.71 \mathrm{~B}$ & $2.7 \pm 0.4 \mathrm{~A}$ & $151.2 \pm 27.8 \mathrm{~A}$ \\
$16 \mathrm{wt} \%$ & $89.87 \pm 0.24 \mathrm{~B}$ & $107.8 \pm 15.8 \mathrm{~A}$ & $2.2 \pm 0.3 \mathrm{~B}$ & $98.8 \pm 18.0 \mathrm{~B}$ \\
\hline
\end{tabular}

Different letters represent statistically significant differences $(p<0.05)$. Uppercase letters refer to columns.

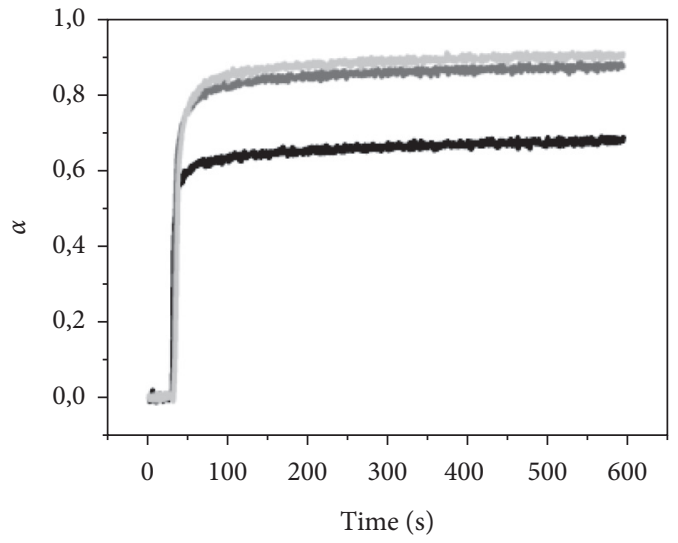

$$
\begin{aligned}
& -0 \% \mathrm{D}_{2} \mathrm{O} \\
& -\quad 10 \% \mathrm{D}_{2} \mathrm{O} \\
& -16 \% \mathrm{D}_{2} \mathrm{O}
\end{aligned}
$$

(a)

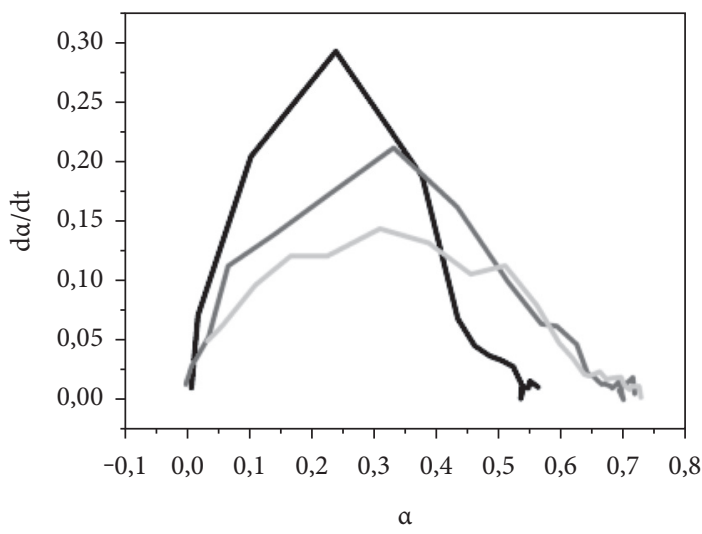

$0 \% \mathrm{D}_{2} \mathrm{O}$

$-10 \% \mathrm{D}_{2} \mathrm{O}$

$16 \% \mathrm{D}_{2} \mathrm{O}$

(b)

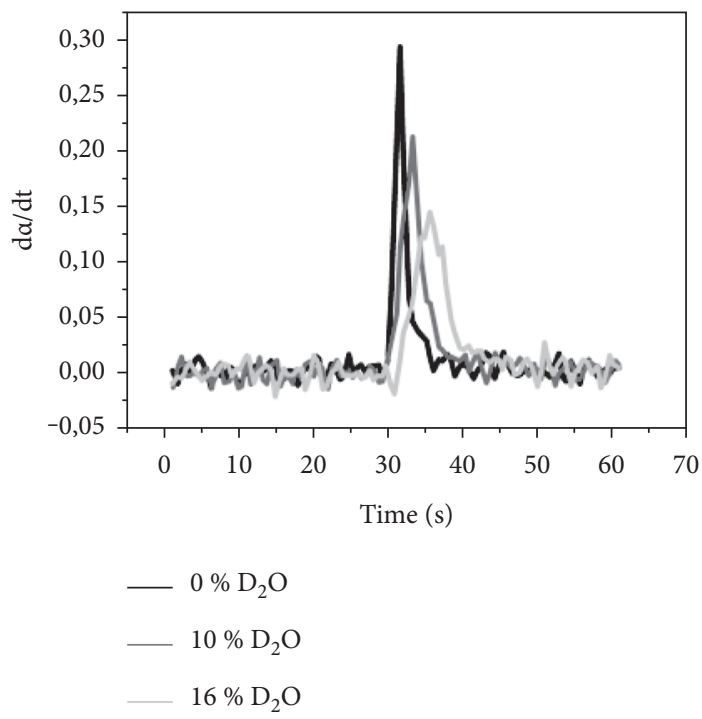

(c)

FIgURE 1: Polymerization kinetics of adhesives with different amounts of deuterium in their formulation: (a) DC over time; (b) polymerization rate by time; (c) polymerization rate by DC. $\alpha$ is the fraction of reacted monomer.

Mean sorption and solubility values obtained for each group in the different aging solutions are presented in Table 3. For the sorption, water and ethanol showed statistical differences in the three adhesives' formulation $(0 \mathrm{wt} \%, 10 \mathrm{wt}$ $\%$, and $16 \mathrm{wt} \% \mathrm{D}_{2} \mathrm{O}$ ). In acetone, experimental adhesives with $0 \mathrm{wt} \%$ and $10 \mathrm{wt} \% \mathrm{D}_{2} \mathrm{O}$ showed significantly less mean values than the $16 \mathrm{wt} \% \mathrm{D}_{2} \mathrm{O}$. Considering the different formulations, experimental adhesive with $16 \mathrm{wt} \% \mathrm{D}_{2} \mathrm{O}$ absorbed more solvent than the $0 \mathrm{wt} \% \mathrm{D}_{2} \mathrm{O}$. Among the solvents, water was the least absorbed by the samples.

Samples with $0 \mathrm{wt} \% \mathrm{D}_{2} \mathrm{O}$ showed lower mean values for the solubility than the $16 \mathrm{wt} \% \mathrm{D}_{2} \mathrm{O}$ in ethanol and acetone 


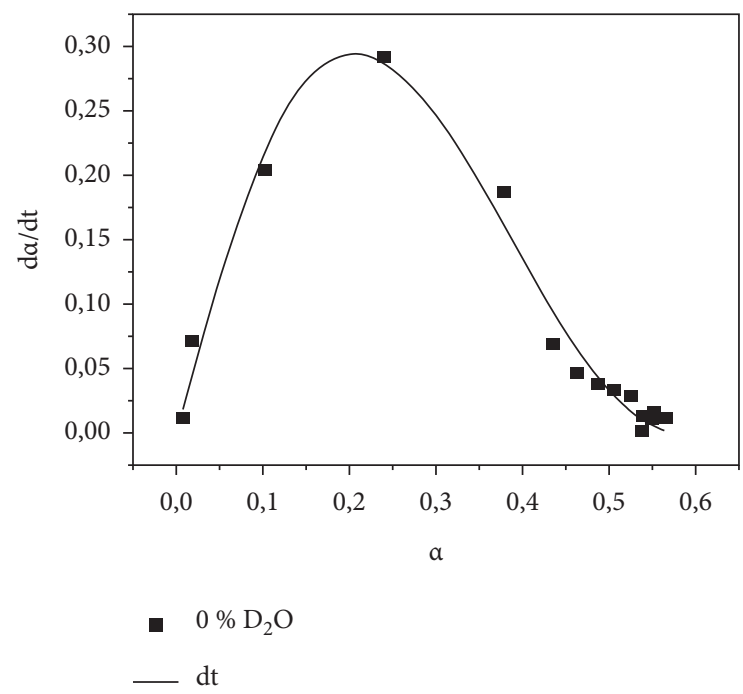

(a)

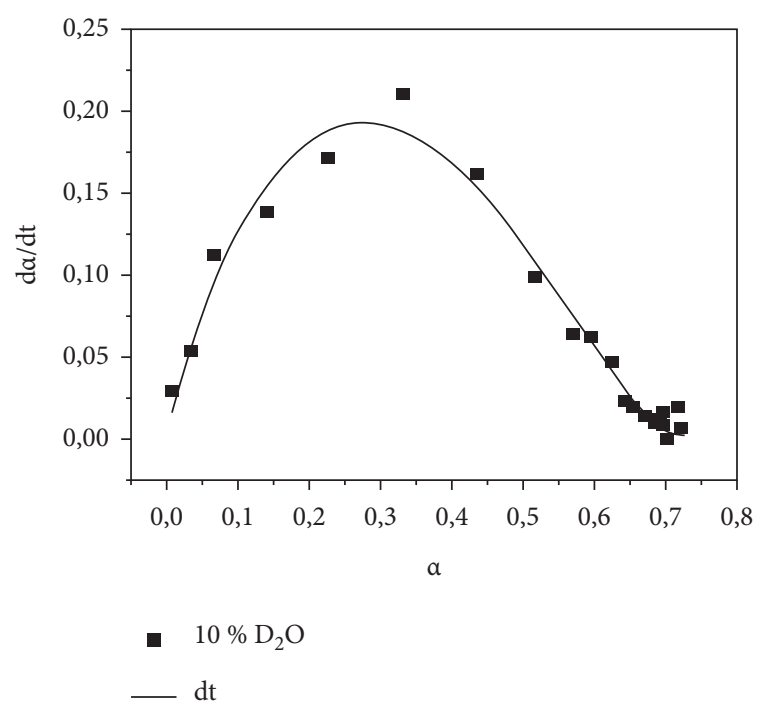

(b)

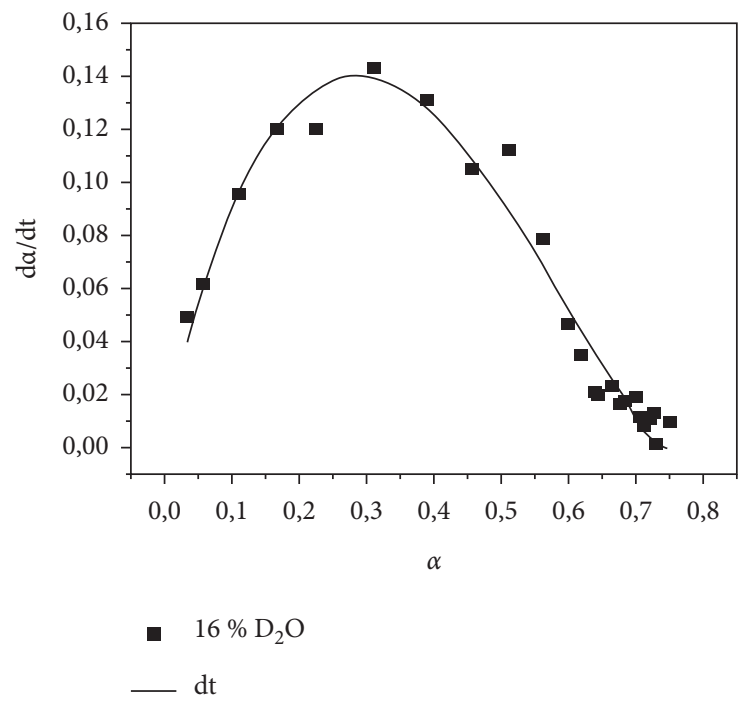

(c)

Figure 2: Polymerization kinetics of adhesive models with different amounts of $\mathrm{D}_{2} \mathrm{O}$ in their formulation.

TABLE 2: Kinetic constants referring to the autocatalytic model adjusted to the experimental results presented in Figure 2.

\begin{tabular}{lcccc}
\hline Adhesive models & $k$ & $m$ & $n$ & $c$ \\
\hline $0 \mathrm{wt} \% \mathrm{D}_{2} \mathrm{O}$ & $15 \pm 9$ & $1.17 \pm 0.17$ & $2.11 \pm 0.47$ & $0.58 \pm 0.03$ \\
$10 \mathrm{wt} \% \mathrm{D}_{2} \mathrm{O}$ & $2.01 \pm 0.53$ & $0.9 \pm 0.1$ & $1.41 \pm 0.2$ & $0.71 \pm 0.02$ \\
$16 \mathrm{wt} \% \mathrm{D}_{2} \mathrm{O}$ & $1.27 \pm 0.32$ & $0.88 \pm 0.1$ & $1.42 \pm 0.2$ & $0.74 \pm 0.02$
\end{tabular}

$k$, speed constant; $m$, exponent of the autocatalytic term; $n$, exponent of the reaction order term; $c$, reaction yield.

but were higher in water. Samples with 10 and $16 \mathrm{wt} \% \mathrm{D}_{2} \mathrm{O}$ were not statistically different from each other, still considering the solubility in all solvents. Among all concentrations ( $0 \mathrm{wt} \%, 10 \mathrm{wt} \%$, and $\left.16 \mathrm{wt} \% \mathrm{D}_{2} \mathrm{O}\right)$, ethanol showed the highest mean values for the solubility when compared with water and acetone.

Figure 3 presents representative graphs of the sorption of the dentin adhesive (\%) in relation to the storage time. The sorption curves of adhesives with $0 \mathrm{wt} \%$ and $10 \mathrm{wt} \% \mathrm{D}_{2} \mathrm{O}$ immersed in water and acetone showed the same characteristics. In the first two days (region A), there was an increase in mass. After that period, there was a little less mass (region $\mathrm{B}$ ) following stabilization (region $\mathrm{C}$ ). The adhesive with $16 \mathrm{wt} \% \mathrm{D}_{2} \mathrm{O}$ immersed in water or acetone showed greater sorption, while the adhesive with $0 \mathrm{wt} \% \mathrm{D}_{2} \mathrm{O}$ immersed in the same media showed less sorption.

The adhesive with $0 \mathrm{wt} \% \mathrm{D}_{2} \mathrm{O}$ immersed in ethanol showed a different behavior from the others. There was an 
TABLE 3: Mean \pm standard deviation and results of Tukey's test for sorption (\% SOR) and solubility (\% SOL) for each experimental group.

\begin{tabular}{lcccccc}
\hline & & & & & \multicolumn{2}{c}{ SOL } \\
& Water & Ethanol & Acetone & Water & Ethanol & Acetone \\
\hline $0 \mathrm{wt} \%$ & $8.6 \pm 0.2 \mathrm{Aa}$ & $20.8 \pm 0.4 \mathrm{Ab}$ & $21.3 \pm 1.7 \mathrm{Ab}$ & $2.1 \pm 0.7 \mathrm{Aa}$ & $5.6 \pm 1.9 \mathrm{Ab}$ & $0.2 \pm 0.4 \mathrm{Ac}$ \\
$10 \mathrm{wt} \%$ & $7.2 \pm 0.3 \mathrm{Ba}$ & $19.7 \pm 0.5 \mathrm{Bb}$ & $22.5 \pm 0.3 \mathrm{Ac}$ & $0.4 \pm 0.2 \mathrm{Ba}$ & $7.0 \pm 0.4 \mathrm{ABb}$ & $4.7 \pm 1.2 \mathrm{Bc}$ \\
$16 \mathrm{wt} \%$ & $11.7 \pm 0.4 \mathrm{Ca}$ & $24.9 \pm 0.7 \mathrm{Cb}$ & $27.8 \pm 1.2 \mathrm{Bc}$ & $0.2 \pm 0.1 \mathrm{Ba}$ & $7.6 \pm 0.4 \mathrm{Bb}$ & $3.3 \pm 2.2 \mathrm{Bc}$ \\
\hline
\end{tabular}

Different letters represent statistically significant differences $(p<0.05)$. Uppercase letters refer to columns; lowercase letters refer to lines.

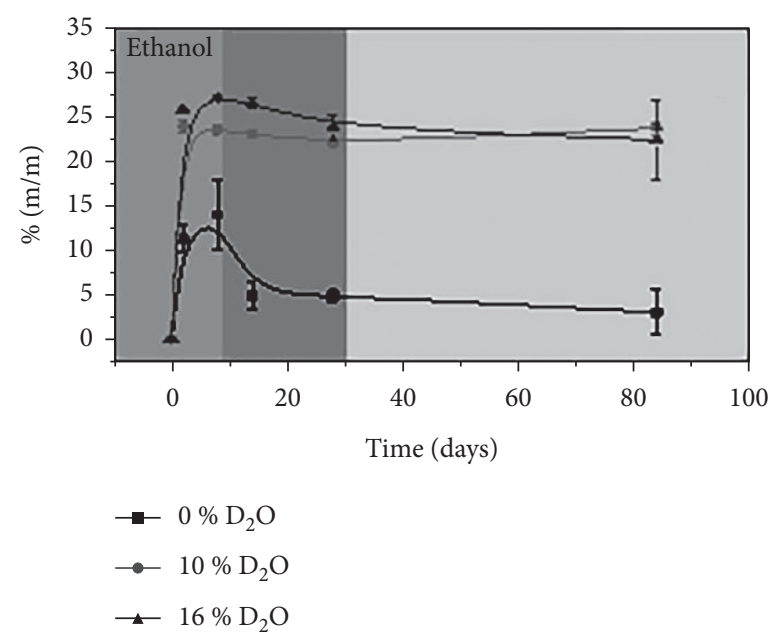

(a)

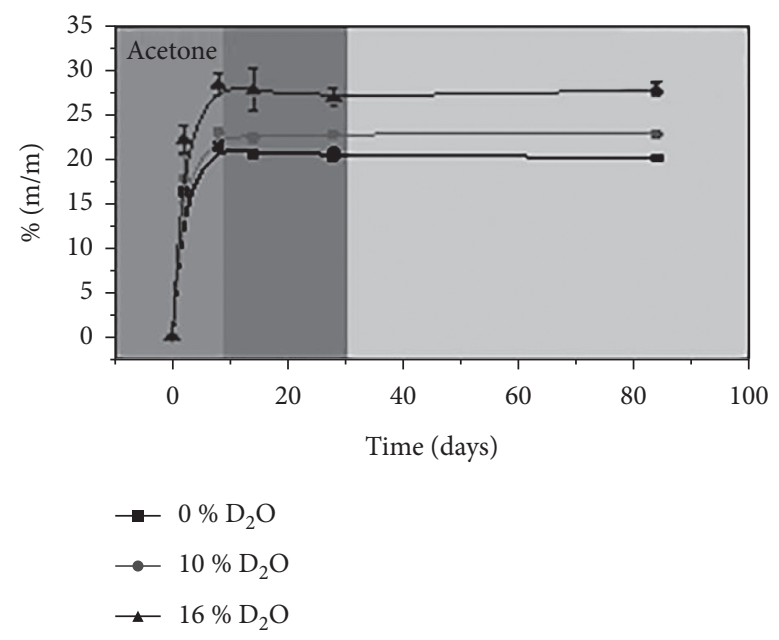

(b)

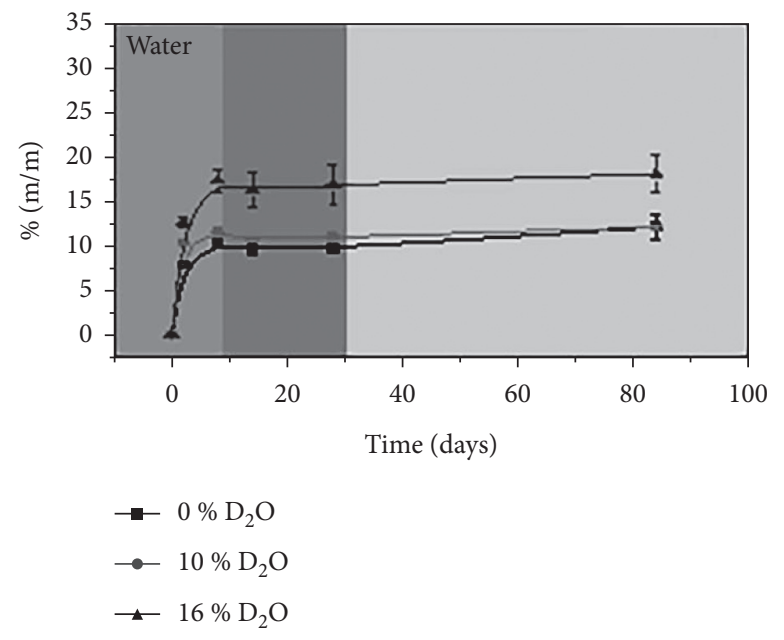

(c)

FIGURE 3: Representative graphs of the sorption of adhesives (\%) in relation to the storage time.

increase in mass until the second day followed by a large drop in sorption, approximately $60 \%$ of the mass absorbed in the first two days. The adhesives with $10 \mathrm{wt} \%$ and $16 \mathrm{wt} \%$ $\mathrm{D}_{2} \mathrm{O}$ showed, respectively, $6 \%$ and $15 \%$ loss of sorption after two days of storage (region B).

\section{Discussion}

The model adhesive resin used in the present study consisted of a mixture of HEMA and BisGMA with a mass ratio of 45/ 55 and photoinitiators [3]. Commercial adhesives were not used because of their unknown and complex composition that may influence results and adversely affect reproducibility $[2,21]$; therefore, a fully known formulation is required to better understand the behavior of the adhesive in the wet simulated clinical environment under aging.

The photoinitiators used for the present study combine hydrophobic (0.5 wt\% CQ as a hydrophobic photosensitizer and 0.5 wt $\%$ EDMAB as a hydrophobic coinitiator) and hydrophilic (1.0 wt\% DPIHP hydrophilic iodonium salt) characteristics and showed good results in relation to the DC of adhesives in the presence of water as observed by previous 
studies [5, 18, 19]. DPIHP as a hydrophilic coinitiator improved the DC and mechanical properties of the adhesives, inducing a better behavior of the hydrophilic-rich phase [22]. This effect was related to its capacity to act as an electron acceptor, regenerating photosensitizer molecules (e.g., CQ) by replacing or generating terminating radicals. The incorporation of hydrophilic photoinitiators in the resin will allow photoinitiators to diffuse more freely within the hydrophilic-rich phases, improving their mechanical properties. However, DPIHP is inactive without the presence of a photosensitizer [22].

Different amounts of $\mathrm{D}_{2} \mathrm{O}$ (heavy water) were added to simulate wet bonding conditions in the dentin and to allow phase separation of the adhesive during light curing. These concentrations of $\mathrm{D}_{2} \mathrm{O}$ were added according to a ternary phase diagram [7], where $0 \mathrm{wt} \% \mathrm{D}_{2} \mathrm{O}$ represents a neat resin, $10 \mathrm{wt} \% \mathrm{D}_{2} \mathrm{O}$ is the limit of macroscopic separation for resin mixture, and in $16 \mathrm{wt} \% \mathrm{D}_{2} \mathrm{O}$, the macrophase separation occurs [5].

The polymerization reaction of an adhesive is a complex mechanism that dramatically influences its structure and properties [22, 23].

For DC, neat resin $\left(0 \mathrm{wt} \% \mathrm{D}_{2} \mathrm{O}\right)$ exhibited the significant lowest values and the highest rate of polymerization when compared with the formulation with $\mathrm{D}_{2} \mathrm{O}$ (Figures 1 and 2), as observed previously $[12,14,24,25]$. This result could be explained due to the enhanced mobility of reactive species in the lower viscosity with the dilution in water $[14,24,25]$. The viscosity of the adhesive model with water content is lower than formulations without water [25]. The polymerization rates decrease with increasing water $\left(\mathrm{D}_{2} \mathrm{O}\right)$ content (Figure 2). The polymerization rate values are the result of the autoacceleration effects in free radical polymerization (gel effect), which is associated with the viscosity of the resin monomer, where higher viscosity would have a higher polymerization rate [15].

When the kinetic constants of the reactions were determined, the exponent of the autocatalytic term did not undergo a significant change by the addition of $\mathrm{D}_{2} \mathrm{O}$. However, the speed constant $(k)$ and the exponent of the reaction order term $(n)$ decrease with the increase of $\mathrm{D}_{2} \mathrm{O}$. The increase in the speed constant $(k)$ caused by the absence of $\mathrm{D}_{2} \mathrm{O}$ may be related to the greater amount of free radicals active in the medium. Regarding the exponent of the reaction order term (n), the loss of speed due to the disappearance of the monomer is linked to a change in the reaction mechanism [18], which can be caused by the chain transfer process. However, the change in the mechanism was beneficial to the adhesive model since it allowed a greater extension of the polymerization reaction, improving its final properties.

The change of mechanism can modify the polymerization reaction speed, and the DC can influence other properties of the adhesive model, such as its interaction with water. When the initiate transfers the chain to $\mathrm{D}_{2} \mathrm{O}$ and starts the polymerization process, this new chain presents an additional hydroxyl when compared to the adhesive model with $0 \mathrm{wt} \% \mathrm{D}_{2} \mathrm{O}$. The increase in hydroxyl groups may favor the process of water permeability in the adhesive (hydrophilia), impacting its durability in the mouth.
The mechanical properties tested, such as the flexural strength [26], modulus of elasticity, and compressive strength $[27,28]$, are considerably important due to the simulation of the mechanical load during chewing. For the flexural strength, the highest mean value was observed in the $10 \mathrm{wt} \% \mathrm{D}_{2} \mathrm{O}$ group, which is statistically different from the 0 wt $\%$ and the $16 \mathrm{wt} \% \mathrm{D}_{2} \mathrm{O}(p=0.0319)$. For the modulus of elasticity, the highest mean value was also in the $10 \mathrm{wt} \% \mathrm{D}_{2} \mathrm{O}$ group and was only statistically different from the $16 \mathrm{wt} \%$ $\mathrm{D}_{2} \mathrm{O}$ group $(p=0.0179)$.

For the compressive strength, the samples should collapse during the application of vertical forces on the long axis of the material [29]. In the present study, only samples with $0 \mathrm{wt} \%$ and $10 \mathrm{wt} \% \mathrm{D}_{2} \mathrm{O}$ collapsed. The specimens with 16 wt $\% \mathrm{D}_{2} \mathrm{O}$ were accommodated according to the load increase and presented only the reduction of height and some cracks. However, even without collapsing, the test was automatically stopped by the universal testing machine.

The compressive strength showed a statistical difference among the concentrations of $\mathrm{D}_{2} \mathrm{O}$ in the adhesive formulation $(p<0.0001)$, where the $16 \mathrm{wt} \% \mathrm{D}_{2} \mathrm{O}$ group showed the lowest values. These results can be explained because in these specimens, there are empty spaces created by the bubbles, leaving the specimens less resistant. This water content (16 wt\%) exceeds the miscibility limit, causing macrophase separation of the adhesive, confirming the findings of Ye et al. [4]. Although the different water content added to the adhesive (10 wt $\%$ and $16 \mathrm{wt} \%)$ did not present significant differences in the propagation and termination of polymerization, the mechanical properties (compression and modulus of elasticity) were more affected with excess water (16 wt\%). The different water $/ \mathrm{D}_{2} \mathrm{O}$ concentrations that may be present in the adhesive contribute to the heterogeneity of the material, and the more heterogeneous the material, the greater the probability that a significantly weaker structure will occur in some regions. It is likely that, during the function, stress will focus on the limit of the two phases. Deterioration of the material can start at the stress concentration sites. Thus, excess water may play a critical role in the integrity and durability of the adhesive/dentin interface under stresses occurring in the oral environment.

For this reason, the first null hypothesis was rejected.

Recognizing the influence of excess water $/ \mathrm{D}_{2} \mathrm{O}$ and types of phases allows us to better understand dental adhesives. Water is present on the dentin surface during the application of the adhesive system in different concentrations since it varies with the structure of the dentin. The sound dentin is different from the affected dentin, varying according to the depth, age of the patient, and even with the skills of the operator. In addition, water is also present in the adhesive composition (as a solvent) and extrinsically in the oral environment [23].

Sorption and solubility analyses are important physical properties to understand the performance of adhesive systems in the oral environment and in the presence of water as well as organic solvents (ethanol or acetone) present in food and beverages [30]. All adhesive formulations under aging solutions presented significant differences in the sorption behavior. All samples exhibited rapid sorption in the first 8 days of immersion (Figure 3). The highest mean values of sorption were presented in the $16 \mathrm{wt} \% \mathrm{D}_{2} \mathrm{O}$ in all solutions. 
This result is also in agreement with Park et al. [14]. It can be explained because in the $16 \mathrm{wt} \% \mathrm{D}_{2} \mathrm{O}$, there are empty spaces where the water is entrapped due to phase separation. When this entrapped water begins to evaporate from the empty pores, they are capable of storing more solutions, accelerating degradation and reducing the mechanical properties [19].

Samples in ethanol and acetone present higher mean values of sorption than samples in water [31]. This result could be associated with the molecular weight: $18 \mathrm{~g} / \mathrm{mol}$ for water, $46 \mathrm{~g} / \mathrm{mol}$ for ethanol, and $58 \mathrm{~g} / \mathrm{mol}$ for acetone. All adhesives' formulations under aging solutions also showed different solubility behavior. Ethanol and acetone seem to compromise the samples more than water. The solvent potential depends on the polarity between the substances [12]. The water solubility parameter is higher than the methacrylate monomers, making it a weak solvent [12, 32], which means that more time would be needed to promote greater plasticization and degradation of the polymers.

The swelling process of a polymer subjected to a medium occurs due to the osmotic effect that the polymer causes; the pure liquid has a lower vapor pressure than the liquid absorbed in the polymer [29]. The behavior of adhesives in region A (Figure 3) showed an increase in the mass of polymers. Subsequently, a loss of mass occurred (region B) due to the migration of unreacted monomers to the solution $[33,34]$. The solvent penetrates the monomers' matrix and led to increased absorption and matrix plasticization, and the unreacted monomers release.

Since the solubility of monomers is greater in ethanol and acetone than in water, the results suggest the ethanol promotes greater sorption (solvent penetrates in the monomer matrix), which leads to greater solubility (hydrophilic and hydrophobic monomers' elution).

Based on the FTIR data, it can be concluded that the adhesive with $0 \mathrm{wt} \% \mathrm{D}_{2} \mathrm{O}$ showed less conversion of monomers into polymers, presenting a greater amount of unreacted monomer between its chains $[33,34]$. The adhesives immersed in water and acetone had a slight mass loss in region $\mathrm{B}$ (Figure 3) because only the HEMA has a high solubility in these media. BisGMA is soluble in ethanol; therefore, the mass loss of adhesive with $0 \mathrm{wt} \% \mathrm{D}_{2} \mathrm{O}$ can be associated with the release of BisGMA to the media. The adhesives with $10 \mathrm{wt} \%$ and $16 \mathrm{wt} \%$ $\mathrm{D}_{2} \mathrm{O}$ did not exhibit this behavior, probably because most of the BisGMA is trapped in the chains. These results are consistent with the DC, indicating that these adhesives showed a greater extent of reaction.

Thus, the second null hypothesis was rejected.

The most effective adhesive systems have hydrophilic monomers and a high concentration of solvents, which may be water, ethanol, or acetone. The recognition and maintenance of wet dentin is difficult to achieve since it depends on the type of solvent on the adhesive as well as the skill and interpretation of the operator in relation to the manufacturer's instructions, drying time, and distance between the tooth and the syringe [35-37]. Excess water may transform the adhesive interface into a semipermeable membrane, highly susceptible to the degrading effects of water [38].

Researchers have established that water-based and water/ethanol-based adhesives have better performance on dry surfaces (such as in endodontic treated teeth) and acetonebased adhesives have better performance on wet surfaces [39]. However, from the clinical point of view, it is practically impossible to accurately determine the ideal surface moisture. Furthermore, the presence of water in the hybrid layer may compromise the formation of a highly crosslinked polymer, making the wetting technique difficult and unpredictable $[6,40]$.

Some investigations show that the bonding of dry demineralized dentin may be an option to reduce the amount of water trapped inside the hybrid layer and the problems of this excess water. Reis et al. [37] observed that it is possible to obtain high bond strength values between the adhesive and air-dried dentin. The friction action can increase component kinetics and allow better diffusion of monomers inward while solvents spread out [34]. ZanderGrande et al. [40] clinically evaluated restorations with adhesion in dry and wet dentin, and the authors concluded that dentin hydration does not have a significant effect on adhesive retention, provided the clinician's vigorously friction action with the adhesives on the dentin surfaces [40].

With the understanding that excess water is extremely detrimental to the different properties of the adhesive, it is necessary to perform more research on the behavior of adhesive systems under the most diverse clinical conditions since it will be subject to excess water in dentin and lack of water in endodontic treated teeth; hypermineralized and whitened dentin; young or old; and healthy, caries-affected, or fractured. The discovery of new components with better hydrophobic and hydrophilic characteristics is also possible.

\section{Conclusion}

The different concentrations of water $\left(\mathrm{D}_{2} \mathrm{O}\right)$ added in the experimental adhesive formulation and aging solvents significantly influence the physicochemical and mechanical properties of the experimental model. The $10 \mathrm{wt} \%$ of water might have positively influenced the degree of conversion, flexural strength, modulus of elasticity, compressive strength, and sorption and solubility of the dentin adhesive model, where excess and lack of $\mathrm{D}_{2} \mathrm{O}$ were harmful to the adhesive [40].

Degree of conversion:

$$
D C(\%)=\left(1-\left(\frac{(1638 c m-1 / 1608 c m-1) \text { cured }}{(1638 c m-1 / 1608 c m-1) \text { uncured }}\right)\right) \times 100
$$


Sorption:

$$
W S(\%)=\left(\frac{m_{s}-m_{i}}{m_{i}}\right) \times 100 .
$$

Solubility:

$$
W L(\%)=\left(\frac{m_{i}-m_{d}}{m_{i}}\right) x 100 .
$$

Autocatalytic processes:

$$
\left(\frac{d \alpha}{d t}=k(\alpha)^{m}(c-\alpha)^{n}\right)
$$

\section{Data Availability}

The data used to support the findings of this study are available from the corresponding author upon request.

\section{Ethical Approval}

The present article does not contain any studies with human participants or animals performed by any of the authors.

\section{Conflicts of Interest}

All authors declare no conflicts of interest.

\section{References}

[1] P. Spencer, Q. Ye, J. Park et al., "Durable bonds at the adhesive/dentin interface:an impossible mission or simply a moving target?" Brazilian Dental Science, vol. 15, no. 1, pp. 4-18, 2012.

[2] B. Van Meerbeek, K. Yoshihara, K. Van Landuyt, Y. Yoshida, and M. Peumans, "From buonocore's pioneering acid-etch technique to self-adhering restoratives. A status perspective of rapidly advancing dental adhesive technology," The Journal of Adhesive Dentistry, vol. 22, no. 1, pp. 7-34, 2020.

[3] P. Spencer and Y. Wang, "Adhesive phase separation at the dentin interface under wet bonding conditions," Journal of Biomedical Materials Research, vol. 62, no. 3, pp. 447-456, 2002.

[4] C. R. Pucci, R. S. de Oliveira, T. M. F. Caneppele, C. R. G. Torres, A. B. Borges, and F. R. Tay, "Effects of surface treatment, hydration and application method on the bond strength of a silorane adhesive and resin system to dentine," Journal of Dentistry, vol. 41, no. 3, pp. 278-286, 2013.

[5] Q. Ye, Y. Wang, and P. Spencer, "Nanophase separation of polymers exposed to simulated bonding conditions," Journal of Biomedical Materials Research Part B: Applied Biomaterials, vol. 88, no. 2, pp. 339-348, 2009.

[6] C. K. Y. Yiu, N. M. King, M. R. O. Carrilho et al., "Effect of resin hydrophilicity and temperature on water sorption of dental adhesive resins," Biomaterials, vol. 27, no. 9, pp. 1695-1703, 2006.

[7] Q. Ye, J. Park, J. S. Laurence, R. Parthasarathy, A. Misra, and P. Spencer, "Ternary phase diagram of model dentin adhesive exposed to over-wet environments," Journal of Dental Research, vol. 90, no. 12, pp. 1434-1438, 2011.

[8] H. Chang, M. K. Guo, and F. H. Kasten, "Stimulation of glutathione depletion, ROS production and cell cycle arrest of dental pulp cells and gingival epithelial cells by HEMA," Biomaterials, vol. 26, no. 7, pp. 745-753, 2005.

[9] A. Paranjpe, L. C. F. Bordador, M.-y. Wang, W. R. Hume, and A. Jewett, "Resin monomer 2-hydroxyethyl methacrylate (HEMA) is a potent inducer of apoptotic cell death in human and mouse cells," Journal of Dental Research, vol. 84, no. 2, pp. 172-177, 2005.

[10] M. Falconi, G. Teti, M. Zago, S. Pelotti, L. Breschi, and G. Mazzotti, "Effects of HEMA on type I collagen protein in human gingival fibroblasts," Cell Biology and Toxicology, vol. 23, no. 5, pp. 313-322, 2007 Sep.

[11] M. Toledano, R. Osorio, E. Osorio et al., "Sorption and solubility testing of orthodontic bonding cements in different solutions," Journal of Biomedical Materials Research Part B: Applied Biomaterials, vol. 76B, no. 2, pp. 251-256, 2006.

[12] H. Y. Marghalani and D. C. Watts, "Viscoelastic stability of resin-composites aged in food-simulating solvents," Dental Materials, vol. 29, no. 9, pp. 963-970, 2013.

[13] Y. Zhang and J. Xu, "Effect of immersion in various media on the sorption, solubility, elution of unreacted monomers, and flexural properties of two model dental composite compositions," Journal of Materials Science: Materials in Medicine, vol. 19, no. 6, pp. 2477-2483, 2008.

[14] J.-G. Park, Q. Ye, E. M. Topp, A. Misra, and P. Spencer, "Water sorption and dynamic mechanical properties of dentin adhesives with a urethane-based multifunctional methacrylate monomer," Dental Materials, vol. 25, no. 12, pp. 1569-1575, 2009.

[15] X. Ge, Q. Ye, L. Song, J. S. Laurence, and P. Spencer, "Synthesis and evaluation of a novel co-initiator for dentin adhesives: polymerization kinetics and leachables study," Journal of Occupational Medicine, vol. 67, no. 4, pp. 796-803, 1989.

[16] J. Park, Q. Ye, E. M. Topp, A. Misra, S. L. Kieweg, and P. Spencer, "Effect of photoinitiator system and water content on dynamic mechanical properties of a light-cured bisGMA/ HEMA dental resin," Journal of Biomedical Materials Research Part A, vol. 9999, no. 4, p. NA, 2009.

[17] J. Park, Q. Ye, V. Singh, S. L. Kieweg, A. Misra, and P. Spencer, "Synthesis and evaluation of novel dental monomer with branched aromatic carboxylic acid group," Journal of Biomedical Materials Research Part B: Applied Biomaterials, vol. 100, no. 2, pp. 569-576, 2012.

[18] A. U. J. Yap and S. H. Teoh, "Comparison of flexural properties of composite restoratives using the ISO and miniflexural tests," Journal of Oral Rehabilitation, vol. 30, no. 2, pp. 171-177, 2003.

[19] X. Guo, Y. Wang, P. Spencer, Q. Ye, and X. Yao, "Effects of water content and initiator composition on photopolymerization of a model BisGMA/HEMA resin," Dental Materials, vol. 24, no. 6, pp. 824-831, 2008.

[20] D. C. Barcellos, B. M. Fonseca, C. R. Pucci, B. d. N. Cavalcanti, E. D. S. Persici, and S. E. d. P. Gonçalves, "Zn-doped etch-andrinse model dentin adhesives: dentin bond integrity, biocompatibility, and properties," Dental Materials, vol. 32, no. 7, pp. 940-950, 2016.

[21] C. N. Satterfield, Chemical Reaction Engineering, Octave Levenspiel, p. 578, Wiley, New York; NY, USA, 1973.

[22] Q. Ye, J. Park, E. Topp, and P. Spencer, "Effect of photoinitiators on the in vitro performance of a dentin adhesive exposed to simulated oral environment," Dental Materials, vol. 25, no. 4, pp. 452-458, 2009.

[23] F. Abedin, Q. Ye, R. Parthasarathy, A. Misra, and P. Spencer, "Polymerization behavior of hydrophilic-rich phase of dentin 
adhesive," Journal of Dental Research, vol. 94, no. 3, pp. 500-507, 2015.

[24] M. Toledano, R. Osorio, E. Osorio, V. Fuentes, C. Prati, and F. García-Godoy, "Sorption and solubility of resin-based restorative dental materials," Journal of Dentistry, vol. 31, no. 1, pp. 43-50, 2003.

[25] M. Okuda, P. N. Pereira, M. Nakajima, J. Tagami, and D. H. Pashley, "Long-term durability of resin dentin interface: nanoleakage vs. microtensile bon strength," Operative Dentistry, vol. 27, pp. 289-296, 2002, PMID: 12022462.

[26] J. Park, J. Eslick, and Q. Ye, "The influence of chemical structure on the properties in methacrylate-based dentin adhesives," Dental Materials, vol. 27, no. 11, pp. 1086-1093, 2011.

[27] U. Ortengren, H. Wellendorf, S. Karlsson, and I. E. Ruyter, "Water sorption and solubility of dental composites and identification of monomers released in an aqueous environment," Journal of Oral Rehabilitation, vol. 28, no. 12, pp. 1106-1115, 2001.

[28] H. Cartwright, Physical Chemistry. By Atkins P, Oxford University Press, Oxford, U.K., 2001.

[29] A. Rudawska, "Adhesives and adhesive joints in industry applications," Intech, vol. 77, 2019.

[30] F. d. C. L. Moreira, N. R. Antoniosi Filho, J. B. d. Souza, and L. G. Lopes, "Sorption, solubility and residual monomers of a dental adhesive cured by different light-curing units," Brazilian Dental Journal, vol. 21, no. 5, pp. 432-438, 2010.

[31] A. U. J. Yap, S. H. L. Tan, S. S. C. Wee, C. W. Lee, E. L. C. Lim, and K. Y. Zeng, "Chemical degradation of composite restoratives," Journal of Oral Rehabilitation, vol. 28, no. 11, pp. 1015-1021, 2001.

[32] A. Reis, G. C. Martins, E. A. de Paula, A. D. Sanchez, and A. D. Loguercio, "Alternative aging solutions to accelerate resin-dentin bond degradation," The Journal of Adhesive Dentistry, vol. 17, no. 4, pp. 321-328, 2015.

[33] Y. Wang and P. Spencer, "Hybridization efficiency of the adhesive/dentin interface with wet bonding," Journal of Dental Research, vol. 82, no. 2, pp. 141-145, 2003.

[34] H. Baharav, D. Abraham, H. S. Cardash, and M. Helft, "Effect of exposure time on the depth of polymerization of a visible light-cured composite resin," Journal of Oral Rehabilitation, vol. 15, no. 2, pp. 167-172, 1988.

[35] J. Perdigão, "Current perspectives on dental adhesion: (1) Dentin adhesion - not there yet," Japanese Dental Science Review, vol. 56, no. 1, pp. 190-207, 2020.

[36] B. Van Meerbeek, K. Yoshihara, K. van Landuyt, Y. Yoshida, and M. Peumans, "From buonocore's pioneering acid-etch technique to self-adhering restoratives. A status perspective of rapidly advancing dental adhesive technology," The Journal of Adhesive Dentistry, vol. 22, no. 1, pp. 7-34, 2020.

[37] A. Reis and A. Pellizzaro, "Impact of adhesive application to wet and dry dentin on long-term resin-dentin bond strengths," Operative Dentistry, vol. 32, no. 4, pp. 380-387, 2007.

[38] F. R. Tay, D. H. Pashley, B. I. Suh, R. M. Carvalho, and A. Itthagarun, "Single-step adhesives are permeable membranes," Journal of Dentistry, vol. 30, no. 7-8, pp. 371-382, 2002.

[39] M. Cadenaro, T. Maravic, A. Comba et al., "The role of polymerization in adhesive dentistry," Dental Materials, vol. 35, no. 1, pp. e1-e22, 2019.

[40] C. Zander-Grande, S. Q. Ferreira, T. R. F. da Costa, A. D. Loguercio, and A. Reis, "Application of etch-and-rinse adhesives on dry and rewet dentin under rubbing action," The Journal of the American Dental Association, vol. 142, no. 7, pp. 828-835, 2011. 